\title{
Earth Observation for Habitat and Biodiversity Monitoring
}

\author{
Stefan $\mathrm{LANG}^{1}$, Christina CORBANE${ }^{2}$ and Lena PERNKOPF ${ }^{1}$ \\ ${ }^{1}$ Department of Geoinformatics - Z_GIS, University of Salzburg/Austria ·stefan.lang@sbg.ac.at \\ ${ }^{2}$ Irstea, UMR TETIS, Montpellier/ France
}

This contribution was double-blind reviewed as extended abstract.

\begin{abstract}
The special workshop "Earth observation for ecosystem and biodiversity monitoring - best practices in Europe and globally, at GI_Forum 2013, focused on the outcomes of the EUfunded projects MS.MONINA and BIO_SOS and related activities that highlight the potential of Earth observation data and technologies in support of biodiversity and ecosystem monitoring. In Europe, nature conservation rests upon a strong, yet ambitious policy framework with legally binding directives. Thus, geospatial information products are required at all levels of implementation. With advances in Earth observation data availability and the forthcoming of powerful data analysis tools we enter a new dimension of satellitebased services. Recent achievements of such endeavours were showcased and challenges discussed, using best practice examples from both inside and outside Europe. This article summarizes the state-of-the-art of satellite-based habitat mapping and accommodates the paper contributions in the current scientific discourse.
\end{abstract}

\section{Biodiversity - A Concept Strong but Challenging to Observe}

Biodiversity, the variety of life forms, has become a key word for shaping and bundling political will. By the end of 2010, it became clear that the former political commitment has failed, as the global society has not managed to halt the loss of biodiversity. But political aims need to be likewise strong as they need to be framed in simple terms to be conceivable by the public at large (LANG 2012). The EU 2020 biodiversity strategy (EUROPEAN COMMISSION 2011) as the European contribution to the COP10 Strategic Plan for Biodiversity 2011-2020, has strengthened its power of implementation as compared to the previous 2010 strategy. Now, a set of verifiable goals are listed, which are closely related to the European Habitats Directive (92/43/EC, short: HabDir). By 2020, the strategy is to double the number of sites with a reported favourable status. HabDir fosters the conservation of natural habitats, fauna and flora in the territory of the Member States (MS). Together with the Birds Directive (2009/147/EC) it is a highly effective legal instrument for nature conservation, as both directives are area intensive in the sense that they apply to the entire territory of the EU and consequently of each MS. The physical expression of this policy framework is a coherent ecological network of special areas of conservation known as Natura 2000. The purpose of the network is to assure the long-term survival of Europe's most precious and threatened species and habitats across Europe. HabDir foresees a 
reporting in regular intervals (currently every six years) to oversee the success of its implementation and to gain pan-European information on the status of biodiversity. Such policies are meant to reach down to the political basis, i.e. to the level of single site managers, and ultimately to each citizen. Only, if responsibility is democratized in such a way, and not left to high-level political decisions, we may succeed safeguarding our "natural capital and life-insurance" (EUROPEAN COMMISSION 2011): biodiversity.

But biodiversity, if thought of as the information content of life, requires adequate technology to be observable. Satellite Earth observation (EO, see next chapter) has started to become a ubiquitous means, a 'democratic tool' to observe what is going on the different levels of political implementation (LANG 2012). Together with standardized ground plots and regular in-situ measurements, it became a powerful monitoring device. Monitoring is a political requirement within the European Directives, but it is more. The democratization of information tools (including 'people as sensors', GOODCHILD 2007) makes monitoring an imminent observation task, to be realized in global observation networks such as GEOSS (Global Earth Observation System of Systems).

\section{Towards EO-Based Services for Habitat Monitoring}

\subsection{GMES/Copernicus - the European civilian EO initiative}

The growing need for the civilian use of satellite remote sensing and other EO technologies has led to the European programme Copernicus (copernicus.eu), formerly known as GMES (Global Monitoring for the Environment and Security), as a conjoint initiative between the European Commission and the European Space Agency (ESA). It builds on European space infrastructure and the technological capability to turn data into information services. The Sentinel family of EO satellites, developed by ESA, will provide global coverage with radar and optical data with a few meters ground resolution. Additional data from satellites of the so-called contributing missions will increase both, the variety of available data types and the temporal coverage with remotely sensed data. But next to the provision of frequently updated satellite data we also require the adequate means for an intelligent usage of such data and an efficient analysis of them (LANG 2008).

The Copernicus initiative under the European Commission's DG Enterprise, has opened a lot of side- and byways to SMEs and individual research organizations, by the stimulation of downstream services. Such downstream services seek new emerging areas, where technology would make a difference. Biodiversity and habitat monitoring make up such an area. The 2010 call in the FP7 SPACE programme has asked for projects to develop preoperational services for those emerging areas. The two collaborative projects MS.MONINA (www.ms-monina.eu) and BIO_SOS (www.biosos.eu), explore EO data combined with data from ground surveys. The idea is to set-up EO-based (pre-)operational, yet economically priced solutions to provide timely information on pressures and impacts, to establish spatial priority for conservation and to evaluate its effectiveness. MS.MONINA fosters advanced EO-based analysis and modelling tools, specifically tailored to user requirements on all levels of policy implementation. Three (sub-)services are offered, the so-called .EU, .State, and .Site level service. We address agencies on EU level (e.g., ETC Biodiv, EEA and DG Environment) providing independent information; national and 
federal agencies in reporting on the entire territory by utilizing an information layer concept; local management authorities by advanced mapping methods for status assessment and change maps (Fig. 1).
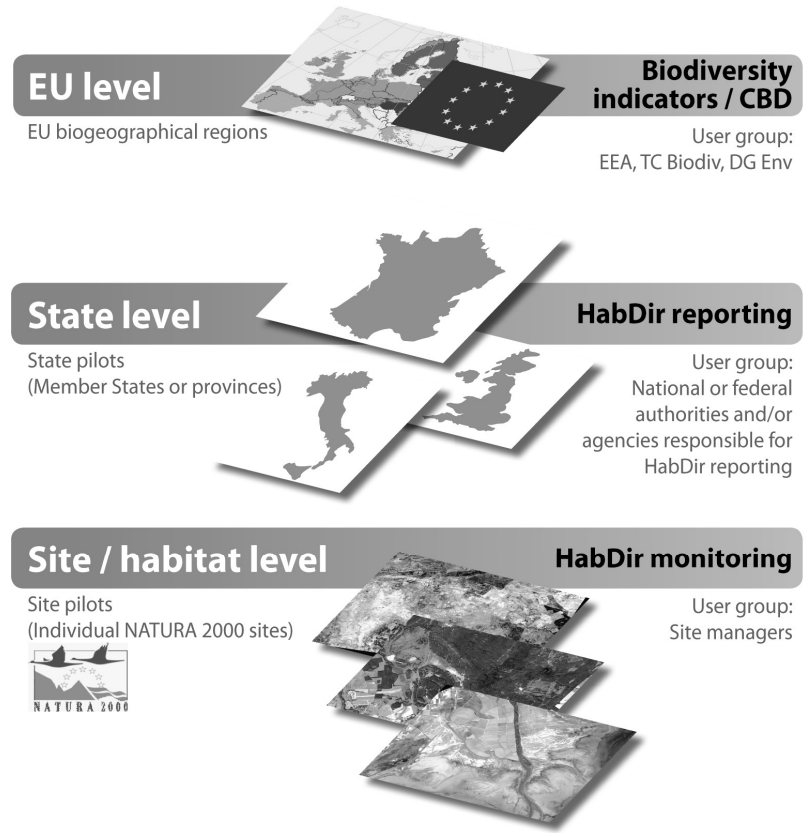

Fig. 1: The MS.MONINA 3-tier service concept. The .site and state level correspond to two different levels (and scales) of service implementation. While the site level explicitly addresses protected areas, such as Natura 2000 sites, the state level provides indicators on habitat distribution for also outside the protected areas (see further details in LANG et al. 2012). The EU level service is designed in such a way that on-demand information can be provided independently from MS reporting.

\subsection{EO capabilities for mapping natural habitats}

To avoid semantic confusion between the concepts of land cover and habitats, which frequently occurs in remote sensing, we start with a definition of either: According to EUROSTAT (2001), land cover "corresponds to a physical description of space, the observed (bio) physical cover of the earth's surface. It is that which overlays or currently covers the ground". Land cover data are usually derived by using multispectral remotely sensed data and statistical clustering methods. Remotely sensed land cover data have been used at different scales (local, regional and global) as input variables for biosphere-atmosphere models and terrestrial ecosystem models and respective change assessments as well as proxies of biodiversity distribution (GRILLO \& VENORA 2011). A habitat on the other hand is a "three-dimensional spatial entity that comprises at least one interface between air, water and ground spaces. It includes both the physical environment and the communities of 
plants and animals that occupy it. It is a fractal entity in that its definition depends on the scale at which it is considered" (BLONDEL 1979). Natural habitats are considered as the land and water areas where the ecosystem's biological communities are formed largely by native plant and animal species and human activity has not essentially modified the area's primary ecological functions (definition according to the European Environmental Agency, EEA). Semi-natural habitats are considered as managed or altered by humans but still 'natural' in terms of species diversity and species interrelation complexity (i.e. diversity).

Plant species respond differently to light emitted by the sun or another artificial energy source, with specific reflection characteristics in the electromagnetic spectrum. In theory, remotely sensed data of adequate spectral and spatial resolution can be used to distinguish different species. A challenging task is to identify the appropriate sensor and the appropriate spectral bands. There are many sources of remotely sensed data used for habitats mapping some of which are typically used extensively for vegetation monitoring. Sensors can be grouped into passive and active sensors, depending on the source of energy involved. Passive sensors record the specific reflectance of sunlight on surfaces while the spectral resolution reflects the number of bands that a sensor is able to acquire from a given part of the electromagnetic spectrum (ranging from panchromatic over multispectral up to hyperspectral sensor systems) Active sensors send an electromagnetic signal and record the travel-time of the sent signal and its reflection by a given surface. Active sensors are differentiated by wavelength into microwave and laser scanning systems. From the perspective of carrier platforms we differentiate between satellite and air-borne sensors. Satellite-based EO systems are further categorized according to their spatial resolution, while the grouping is relative to the highest technical resolution and thereby subject to change. Over the last years, the term 'very high resolution' (VHR) has been used for images with a resolution around or smaller than $1 \mathrm{~m}$. We speak of high resolution (HR) images at resolution levels of up to $5 \mathrm{~m}$. The highest resolution operationally available is around $0.5 \mathrm{~m}$.

While other sensor types do have their specific advantages, the above mentioned projects particularly focus on the use of multispectral HR and VHR images. Multispectral sensors have been used since several decades collecting data fairly broad wavebands (typically 4 to recently 8). Multispectral data taken by spaceborne sensors (e.g., Landsat 7, ASTER, IKONOS, SPOT-5, Worldview-2, Quickbird-2, Rapideye) are useful for land cover assessments of from local to regional scale (depending on the spatial resolution). Such data are being used to assess habitat conditions for monitoring purposes (FÖRSTER et al. 2008; FRANKE et al. 2012; SPANHOVE et al. 2012). Advanced studies investigate spectral characteristics of specific sensors for such tasks (e.g., SCHUSTER et al. 2012), and addressed the suitability of multispectral data for an assessment of detailed floristic variation. NAGENDRA \& RoCCHINI (2008) used multispectral sensors to see to what extent the spectral information of multispectral data allows for a detailed assessment of the variable floristic composition within a certain natural habitat (mainly grassland and wet heath and floodplain meadows). Tree species differentiation has been accomplished using 8-band WorldView-2 data for forest management in general (IMITZER et al. 2012) and riparian forest assessment in particular (STRASSER et al. 2012, RIEDLER et al. 2013, this volume). 


\subsection{Broad and detailed habitat mapping using remote sensing technology}

Reproducibility, objectivity, transferability and the increased possibility for quantification have been reported as the main advantages of mapping approaches based on EO data (LANG \& LANGANKE 2006). Semi-automated classification methodologies for EO data (such as object-based image analysis, LANG 2008; SMITH et al, 2013, this volume) set the foundation for better transferable and more transparent image classifications as compared to visual interpretation. Over recent years, great advantages have been reported in the use of remote sensing technology for the mapping and the assessment of habitats in Europe (for an overview see VANDEN BORRE et al. 2011). This likewise applies to different broad habitat types (forests, grasslands, wetlands, etc.) and different scales of observations as fine as subhabitat level (LUCAS et al. 2011).

Mapping of broad habitat types (forests, grasslands, shrubs, etc.) using remote sensing is a common and many studies can be reported on the topic of broad habitats classification. In JELASKA et al. (2005) an integrated use of Landsat and field data allowed the classification of thirteen plant communities or their combinations in a nature park in Croatia. Satellite and airborne data integrated with ground measurements were used for mapping natural vegetation communities in the Pollino National Park (Southern Italy) (LA NORTE et al. 2002). On the basis of multi-temporal Landsat images and a fusion of SPOT panchromatic data with the Landsat, several vegetation classes (including different forest types, maquis classes differentiated by their average heights, pseudo-steppe and scrub vegetation) were recognized (GRIGNETTI et al. 1997). A decision tree classifier incorporating, optical and microwave remote sensing data as well as DEM and soil information was developed for the classification of broad habitat classes in Finland (HATUNEN et al. 2008). The classified habitats were pine, spruce, deciduous forests, two classes of mountain birch, open bog, grasslands, heathlands and open rocks. Among the limited number of studies that addressed the automatic classification of aerial photos for broad habitats mapping, the work of (CHAPMAN et al. 2009) was rather unique. The authors used exclusively colour and infrared aerial photographs which were acquired over the open upland moors in Great Britain. The aerial photos were automatically classified into seven dominant land cover classes (e.g., newly burnt heather; pioneer/early building heather; late building/mature heather; degenerate heather; bracken; grasses; sedges/rushes; bare peat, etc.) using the Random Forest ensemble machine learning algorithm.

Few studies succeeded in mapping the distribution of several detailed habitat types and vegetation communities in Europe using direct remote sensing approaches. Already in 2003, BocK (2003) attempted to use Landsat imagery to define spectrally homogeneous vegetation types (e.g., meadows, woody brushes, coniferous and grassland) and then to establish a content-wise correspondence of these classes with the biotope and use types. Compared to the aerial photographs the classification showed a generalized model of vegetation and habitat. The major limitation was in the recognition of woody scrubs on water-logged soils that were partly under- or overestimated. In KERAMITSOGLOU et al. (2005), a kernel-based re-classification algorithm was developed and tested on several Natura 2000 sites, located within different biogeographical regions, using very high resolution imagery to map fine scale habitats according to the EUNIS classification scheme (EUROPEAN COMMISSION, DG ENVIRONMENT 2003). POLYCHRONAKI et al. (2013, this volume) investigated the performances of different classification methods for land-cover mapping using high resolution data. Findings suggest that the inclusion of solar radiation 
layers in the classification procedure as well as the use of multi-temporal images improves the classification accuracy. CORBANE et al (this volume) tested a method called the Sparse Partial Least Square Discriminant Analysis (SPLSDA). This improved method performs feature selection and classification in a one-step procedure. BocK et al. (2005) were able to successfully distinguish between calcareous grassland (E1.2) and mesotrophic pastures (E2.1) that are known to be difficult to discriminate. Their method was based on an objectbased classification using Quickbird very high resolution satellite data. The work of LUCAS et al. (2011) is thought to be the first study to successfully map up to 105 sub-habitat types at a nominal resolution of $5 \mathrm{~m}$ through an object-oriented rule-based classification of multiresolution and multi-date satellite imagery. Mapping of several habitat types has been largely addressed through mapping of one or a few dominant species in the upper canopy (NAGENDRA 2001) or by establishing links with their broader biophysical characteristics (e.g., seasonal differences in the relative amounts of photosynthetic and/or nonphotosynthetic components; LUCAS et al. 2011). Mapping in less complex habitat mosaics is relatively straightforward (LENGYEL et al. 2008) but is far more challenging where landscapes are more heterogeneous and fine-grained and variation between habitats is more continuous (DÍAZ VALERA et al. 2008). The structure and complexity of landscapes also often differs between the protected areas and their surroundings and different approaches to mapping often need to be considered.

For a comparison of different habitat classification schemes see KALLIMANIS et al. (this volume). ADAMO et al. (2013, this volume) illustrate how remote sensing data can be used to translate land cover maps to habitat maps and also TOMASELLI et al. (2013, this volume) investigate the extent to which common LC/LU taxonomies can be translated to habitat taxonomies with minimum use of additional environmental attributes and/or in situ data.

\section{The EO4Hab Workshop}

"Global change" - a short formula for a multitude of anticipated shifts in societal and environmental domains due to global drivers - calls for spatial monitoring and modelling techniques to better understand the implications and potential dynamics of such changes. International programmes and visions (GEO, GMES/Copernicus, SEIS, etc.) envisage unified systems based on quality standards for data, products and services to establish optimized observation and forecasting capacity within Europe, but also globally. The special workshop at GI_Forum 2013 focuses on the outcomes of the FP7 projects MS.MONINA and BIO_SOS (see BLONDA, this volume) and related activities that highlight the potential of $\mathrm{EO}$ data and technologies in support of biodiversity and ecosystem monitoring. In Europe, nature conservation rests upon a strong, yet ambitious policy framework with legally binding directives. Thus, geospatial information products are required at all levels of implementation. With recent advances in EO data availability and the forthcoming of powerful data analysis tools we enter a new dimension of satellite-based services. Recent achievements of such endeavours are showcased and challenges discussed, using best practice examples from both inside and outside Europe.

The papers presented at this workshop resemble a completing mosaic of promising EObased applications in support to habitat monitoring requirements. And it is no longer limited to mere scientific or lab-constraint exercising. In fact the Copernicus projects that 
evoke a strong user involvement, seek for benchmarking such information services at their maturity level for user workflows. In this sense 'user validation' (see SCHRÖDER et al., this volume) is more than an objective measurement of accuracy or delivery time, it includes the fitness for usage in the daily tasks and routines.

The workshop shall demonstrate how satellite remote sensing can significantly contribute to the monitoring of biodiversity and to meeting the requirements of European policies such as Natura 2000 and the 2020 EU Biodiversity Strategy. Remote sensing techniques have been extensively used in scientific applications related to ecology and conservation (KERR \& OSTROVSKY 2003) with derived indicators on habitat conditions and their biophysical parameters, as well as natural and human-induced change dynamics. Still, in operational context the use of remote sensing for detailed and complete conservation status assessment and monitoring of natural habitats is still rarely exploited (VANDEN BORRE et al. 2011). Therefore this workshop will encourage both scientists and practitioners to better utilize the strengths of EO-based solutions for habitat mapping.

\section{References}

Blondel, J. (1979), Biogeógraphie et écologie: synthèse sur la structure, la dynamique et l'évolution des peuplements de vertébrés terrestres. Paris, New York, Masson.

Bock, M. (2003), Remote sensing and GIS-based techniques for the classification and monitoring of biotopes: Case examples for a wet grass- and moor land area in Northern Germany. Journal for Nature Conservation, 11, 145-155.

Bock, M., Rossner, G., Wissen, M., Remm, K., Langanke, T., Lang, S., Klug, H., BLASCHKE, T. \& VRŠČAJ, B. (2005), Spatial indicators for nature conservation from European to local scale. Ecological Indicators, 5, 322-338.

Chapman, D. S., Bonn, A., Kunin, W. E. \& CoRnell, S. J. (2009), Random Forest characterization of upland vegetation and management burning from aerial imagery. Journal of Biogeography, 37, 37-46.

díaz Varela, R., Ramil Rego, P., Calvo Iglesias, S. \& Muñoz Sobrino, C. (2008), Automatic habitat classification methods based on satellite images: A practical assessment in the NW Iberia coastal mountains. Environmental Monitoring and Assessment, $144,229-250$.

EUROPEAN COMMISSION (2011), COM (2011) 244 final, Our life insurance, our natural capital: an EU biodiversity strategy to 2020.

EUROPEAN COMMISSION, DG ENVIRONMENT (2003), Interpretation manual of European Union habitats.

Förster, M., Frick, A., Walentowski, H. \& Kleinschmit, B. (2008), Approaches to utilising QuickBird data for the monitoring of NATURA 2000 habitats. Community Ecology, 9, 155-168.

Franke, J., Keuck, V. \& Siegert, F. (2012), Assessment of grassland use intensity by remote sensing to support conservation schemes. Journal for Nature Conservation, 20, 125-134.

GoodchILD, M. F. (2007), Citizens as sensors: the world of volunteered geography. GeoJournal, 69 (4), 211-221. 
Grignetti, A., Salvatori, R., Casacchia, R. \& Manes, F. (1997), Mediterranean vegetation analysis by multi-temporal satellite sensor data. International Journal of Remote Sensing, 18, 1307-1318.

Grillo, O. \& VENORA, G. (2011), Biodiversity loss in a changing planet. InTech, Rijeka, Croatia.

HAtunen, S., HÄRMÄ, P., KAllio, M. \& TÖRMÄ, M. (2008), Classification of natural areas in northern Finland using remote sensing images and ancillary data. In: Proc. SPIE 7110, Remote Sensing for Environmental Monitoring, GIS Applications, and Geology VIII, 71100W.

Jelaska, S. D., Kušan, V., Peternel, H., Grgurić, Z., Mihulja, A. \& Major, Z. (2005), Vegetation mapping of Žumberak - Samoborsko gorje Nature Park, Croatia, using Landsat 7 and field data. Acta Botanica Croatica, 64, 303-311.

Keramitsoglou, I., Kontoes, C., Sifakis, N., Mitchley, J. \& Xofis, P. (2005), Kernel based re-classification of Earth observation data for fine scale habitat mapping. Journal for Nature Conservation, 13, 91-99.

KerR, J. T. \& Ostrovsky, M. (2003), From space to species: ecological applications for REMOTE SENSING. Trends in Ecology \& Evolution, 18, 299-305.

LANG, S. (2008), Object-based image analysis for remote sensing applications: modeling reality - dealing with complexity. In: BlaschKe, T., LANG, S. \& HAY, G. (Eds.), Object-Based Image Analysis - Spatial concepts for knowledge-driven remote sensing applications. Springer, Berlin, 3-28.

LANG, S. (2012), Ecology Technology - Monitoring Europe's most precious habitats. In: Public Service Review, 12, 361.

LANG, S. \& LANGANKE, T. (2006), Object-based mapping and object-relationship modeling for land use classes and habitats. Photogrammetrie - Fernerkundung - Geoinformation, $1 / 2006,5-18$.

Lang, S., Vanden Borre, J., Haest, B., Pernkopf, L., Buck, O. Pakzad, K., M. FÖRSTER, M. \& HENDRIX. R. (2012), Multi-scale Service for Monitoring NATURA 2000 Habitats of European Community Interest (MS.MONINA). In: SCHULTEBRAUCKS, R., BREGER, P. \& BISCHOFF, H. (Eds.), Let's embrace space - volume II.

La Norte, A., Pignatti, S. \& Tramutoli, V. (2002), Environmental mapping of Pollino National Park (southern Italy) by means of airborne remotely sensed data. In: Schaefer, K., Kohnle, A., Serpico, S. B., Berghmans, F., Fujisada, H., Owe, M., Ehlers, M., Schreiber, U., Posa, F., Bostater, C. R. et al. (Eds.), 290-297.

Lengyel, S., DÉri, E., VARGA, Z., HorvÁth, R., TÓthmérész, B., Henry, P.-Y., Kobler, A., Kutnar, L., BABIJ, V., SEliŠKAR, A. et al. (2008), Habitat monitoring in Europe: a description of current practices. Biodiversity and Conservation, 17, 3327-3339.

Lucas, R., Medcalf, K., Brown, A., Bunting, P., Breyer, J., Clewley, D., Keyworth, S. \& Blackmore, P. (2011), Updating the Phase 1 habitat map of Wales, UK, using satellite sensor data. ISPRS Journal of Photogrammetry and Remote Sensing, 66, 81102.

NAGENDRA, H. (2001), Using remote sensing to assess biodiversity. International Journal of Remote Sensing, 22, 2377-2400.

NAGENDRA, H. \& RoCCHINI, D. (2008), High resolution satellite imagery for tropical biodiversity studies: the devil is in the detail. Biodiversity and Conservation, 17, 34313442. 
Schuster, C., Förster, M. \& Kleinschmit, B. (2012), Testing the red edge channel for improving land-use classifications based on high-resolution multi-spectral satellite data. International Journal of Remote Sensing, 33, 5583-5599.

Spanhove, T., Vanden Borre, J., Delalieux, S., Haest, B. \& PaelinckX, D. (2012), Can remote sensing estimate fine-scale quality indicators of natural habitats? Ecological Indicators, 18, 403-412.

Strasser, T., Lang, S., Pernkopf, L. \& Paccagnel, K. (2012), Object-based class modeling for assessing habitat quality in riparian forests. In. Proceedings of GEOBIA 2012 International Conference on GEographic Object-Based Image Analysis, 555-560.

Vanden Borre, J., PaelinckX, D., Mücher, C.A., Kooistra, L., Haest, B., De Blust, G. \& SCHMIDT, A. M. (2011), Integrating remote sensing in Natura 2000 habitat monitoring: Prospects on the way forward. Journal for Nature Conservation, 19, 116125. 